\begin{tabular}{c|c|c|}
\hline \hline & MARINE ECOLOGY PROGRESS SERIES \\
Vol. 234: 171-181, 2002 & Mar Ecol Prog Ser & Published June 3 \\
\hline \hline
\end{tabular}

\title{
Feeding mechanisms in the gastropod Crepidula fecunda*
}

\author{
O. R. Chaparro ${ }^{1, * *}$, R. J. Thompson ${ }^{2}$, S. V. Pereda ${ }^{1}$ \\ ${ }^{1}$ Instituto de Biología Marina ‘Dr. J. Winter', Universidad Austral de Chile, Casilla 567, Valdivia, Chile \\ ${ }^{2}$ Ocean Sciences Centre, Memorial University of Newfoundland, St. John's, Newfoundland A1C 5S7, Canada
}

\begin{abstract}
The gastropod Crepidula fecunda feeds in 2 distinct ways: grazing of the substrate and suspension feeding. The taenioglossan radula plays a role in both processes. In the former, the radula rasps the surface, and the material is immediately ingested. This means of food acquisition is mainly used by motile individuals, i.e. juveniles and adult males. Adult females are sessile, and are only able to rasp the area beneath the head region, severely limiting the amount of food acquired. Females brooding egg capsules are even more restricted, since the area normally grazed is occupied by the capsule mass. The second mode of feeding, suspension feeding, is exhibited by late juveniles and all adults. Suspended particles are captured in mucous nets on the ventral and dorsal surfaces of the single gill lamella. The entrained particles, loosely bound in mucus, are transported by ciliary action to the distal tips of the filaments, which are bulbous. The material accumulates in 2 mucous strings which traverse the ventral surfaces of the filaments at right angles to the filaments along the entire length of the distal margin of the gill. These strings coalesce into a single, thicker string, which is transferred at intervals to a food canal in the neck, where it is twisted into a compact, mucous cord by a spiral action of the neck canal musculature. The cord is moved through the neck canal to the buccal region, where it is grasped by the radula and ingested. Some material from the gill does not enter the neck canal but is carried by ciliary tracts to a modified region in the mantle, the food pouch, where it is compacted into a mucous ball, which is picked up by the radula and either ingested or rejected as pseudofaeces. In the case of rejection, the ball is pushed to the shell margin by the radula and lips. In C. fecunda food material is stored on the gill, allowing the radula time to undertake other tasks such as rasping the substrate and handling the mucous ball in the food pouch. This dual feeding mechanism diversifies the food and probably increases its nutritional value.
\end{abstract}

KEY WORDS: Crepidula fecunda $\cdot$ Feeding mechanisms

Resale or republication not permitted without written consent of the publisher

\section{INTRODUCTION}

The class Gastropoda is very diverse and has radiated to colonise a variety of aquatic and terrestrial habitats. Plasticity of form and function has certainly been a major factor in the success of this group (Kohn 1983). The exploitation of the nutritional resources characteristic of each environment has resulted in the evolution of several feeding structures and mecha-

\footnotetext{
*Video images of feeding processes are archived on the Inter-Research website (www.int-res.com/journals/suppl/ m234p171videos)

${ }^{* *}$ E-mail: ochaparr@mercurio.uach.cl
}

nisms, e.g. radula, gill (suspension feeders), abrasive teeth and probosces (suction and boring), each adapted to a specific food source (see review by Kohn 1983).

Most species of marine invertebrates exhibit only one mode of feeding in the adult stage. Very rarely are there 2 completely distinct modes, and in such cases the question arises whether they can operate at the same time and whether they exploit the same or different sources of food. In the genus Crepidula (Gastropoda: Calyptraeidae) the gill has acquired a secondary role of suspension feeding (Newell \& Kofoed 1977, Hughes 1986, Eyster \& Pechenik 1988). Some authors have suggested that this mode of feeding may be supplemented by the scraping of food material from

(C) Inter-Research $2002 \cdot$ www.int-res.com 
the substrate by the radula, although there appears to be no unequivocal evidence for this (Hoagland 1979, Chaparro et al. 1998). However, it has been established that the radula is responsible for transferring food from the gill to the mouth (Orton 1912, Werner 1953, Purchon 1977). Many Crepidula species exhibit motile and non-motile stages that are associated with protandry (Hoagland 1978, Fretter 1984, Chaparro et al. 1998). The youngest adults are males that move in order to copulate with females, which form the base of the stack of limpets (Coe 1953, Hendler \& Franz 1971, Hoagland 1979). If food is indeed acquired directly by the radula, males would be able to take advantage of this locomotory phase to obtain food by rasping the substrate (Putnam 1964, Hoagland 1979, Chaparro et al. 1998). The females, however, are completely sessile, at least during the incubation period, and sometimes permanently (Coe 1953, Gallardo 1977, Hoagland 1978, 1979). This sessile habit is associated with parental care of the capsules, which are deposited on the substrate beneath the shell of the female (Gallardo 1977, Cañete \& Ambler 1992). Owing to the restriction imposed by this parental care, the female limpet is unable to move around in search of new areas of substrate to graze with the radula (assuming that the radula is used for this purpose), although rasping may contribute slightly to the nutrition of the female by exploiting the biofilm growing on the underlying substrate (Chaparro et al. 1998).

Thus in Crepidula there is evidence that both the gill and the radula participate in feeding, the former through the entrainment of particles, the latter by transferring all the acquired food material to the mouth (Orton 1912, Werner 1953, Purchon 1977). However, there is little information on the mechanisms involved and the precise roles of the various feeding structures. In particular, it has not been shown unequivocally that food is acquired directly from the substrate by the radula, and this point must be resolved before a complete understanding of feeding in the genus Crepidula can be achieved. The objective of this study was to clarify the roles of the various structures involved in food acquisition by $C$. fecunda, a species from southern Chile.

\section{MATERIALS AND METHODS}

Collection of animals. Specimens of Crepidula fecunda Gallardo 1979 were collected from the intertidal zone in the Bahía de Yaldad, Chiloé, southern Chile $\left(45^{\circ} 5^{\prime} \mathrm{S}, 75^{\circ} 43^{\prime} \mathrm{W}\right)$ and transported to the laboratory at the experimental station of the Universidad Austral de Chile at Quempillén, where they were held in tanks of running seawater under ambient conditions $\left(17^{\circ} \mathrm{C}, 30 \%\right.$ salinity, unfiltered).
Direct observations by microscopy. Adult limpets were detached from the natural substrate, placed on transparent glass plates and held for several days, during which time they normally reattached to the glass. For observation, individuals were transferred to separate small dishes and viewed from the ventral surface through the glass plate. Laboratory-cultured algae (Isochrysis galbana) were added to the water to stimulate feeding. Mucous strands and cords on the gills and other feeding structures were visible under these conditions, but when images were required for demonstration or publication purposes contrast was increased by introducing a suspension of small amounts of nontoxic, light-reflective red plastic particles (2 to $10 \mu \mathrm{m}$ diameter) with a Pasteur pipette in the vicinity of the gill. Observations were made with a Zeiss stereomicroscope fitted with a charge-coupled device (CCD) colour camera (Pulnix) connected to a VHS video recorder and monitor. Video sequences were archived for subsequent analysis.

Videoendoscopy. Twenty large specimens set aside for videoendoscopy were not removed from the natural substrate, although they were held under the same conditions as the others. A small piece of shell was removed from each limpet to allow entry of the optical insertion tube (1.7 $\mathrm{mm}$ diameter) of the endoscope into the appropriate region of the pallial cavity. In some cases it was necessary to remove part of the substrate below the anterior region of the animal. For observation with the endoscope, limpets were placed in separate glass dishes containing a suspension of unicellular algae in seawater. A few drops of a suspension of red plastic particles in seawater were added to the dish at intervals with a Pasteur pipette, greatly improving the visibility of food material bound in mucus. The experimental apparatus was similar to that described by Ward et al. (1991). The endoscope (Olympus SES 1711D) with C-mount zoom adaptor (Schölly fiberoptic) and CCD monochrome camera (model 4815, Cohu Electronics) was mounted on a micromanipulator to permit finely controlled positioning of the optical insertion tube. The endoscope was coupled to a cold halogen light source with a fibre-optic cable and the camera was connected to a VHS video recorder and a monitor. The maximum magnification of the system was ca. 200x. Video sequences were archived for subsequent analysis.

The velocity of food particles on the gill was measured by analysis of video sequences obtained by endoscopy. For each observation, a conspicuous particle was selected and its movement from one defined point on the gill to another was tracked through consecutive frames. The distance traversed by the particle was determined by reference to direct measurements of filament width and interfilament space made with a 
microscope fitted with an eyepiece graticule and calibration slide. The time taken by the particle to travel this distance was obtained from the number of frames in the sequence (NTSC standard $=30$ frames $\mathrm{s}^{-1}$ ). Particle velocity $\left(\mu \mathrm{m} \mathrm{s}^{-1}\right)$ was calculated as distance travelled $(\mu \mathrm{m})$ divided by time taken (s). The procedure was repeated for at least 20 particles and a mean value was obtained.

Light microscopy. The necks and gills of several limpets were excised and placed in Bouin's fixative made up in seawater. The fixed specimens were dehydrated in an ethanol series, cleared in toluene and embedded in paraffin wax. Sections (ca. $7 \mu \mathrm{m}$ ) were cut on a microtome, stained with haematoxylin and eosin and examined with a Zeiss photomicroscope.

Scanning electron microscopy. Small pieces of tissue from the gill, neck and food pouch region were removed and fixed in ice-cold $2 \%$ glutaraldehyde for $2 \mathrm{~h}$. Fixed samples were washed in 0.1 M phosphate buffer, dehydrated in an ethanol series, dried at the critical point, mounted, sputter coated with gold and examined with a Leo 420 scanning electron microscope (SEM).

\section{RESULTS}

\section{The radula}

Crepidula fecunda possesses a taenioglossan radula with transverse rows of 7 teeth arranged in the form 2-1-1-1-2 (Fig. 1). Motile individuals (all males) were observed using the radula to graze the biofilm from the substrate and possibly from the shells of the conspecifics in the chain. Normally the grazing male limpet extends the head and neck beyond the shell margin to increase the area of substrate available, but the radula also rasps material from the substrate located beneath the shell. The latter is the only means by which a sessile female can obtain food from the substrate, since she does not extend the head beyond the shell margin. When incubating egg capsules, the female is unable to use the radula at all for feeding, since the area that would normally be available for grazing is occupied by the capsules. Grazing of the substrate immediately below the head may also be a means by which the female prepares the surface before depositing capsules. Higher rates of grazing were recorded in motile males (mean \pm SD: $234 \pm 123$ radula rasping cycles $\mathrm{h}^{-1}$; shell length 12 to $14 \mathrm{~mm}$ ) than in sessile, non-incubating females (55 \pm 32 radula cycles $\mathrm{h}^{-1}$; shell length 33 to $38 \mathrm{~mm}$ ).

In addition to acquiring food directly by rasping the substrate, the radula plays an important role in suspension feeding by Crepidula fecunda. Particles entrained on the gill are enveloped in a mucous string, which is transferred to a food canal in the neck, where it is compacted into a mucous cord and transported to the mouth. The radula effects the ingestion of the material as the mucous cord emerges from the food canal.

\section{The gill}

The gill is fan shaped and is inserted into the mantle in the median left anterior region (Fig. 2). The area occupied by the branchial filaments is restricted at the distal margin by the foot. Thus the gill lies anterior to the foot and above the neck and head. There is a single lamella (Fig. 3) and the filaments are identical in form, varying only in size, the largest being located in the central region of the gill and the shortest at the sides (both right and left). There are few connections between adjacent filaments, and the animal can adjust the position of the filaments temporarily. The tip (distal region) of each filament is modified as a bulb with a small lateral projection, which fits into a depression in the adjacent anterior filament (Fig. 4). Nevertheless, the connection between neighbouring filaments is weak and can be readily broken by the animal at any time.

The branchial filaments, including the smallest, bear ventral, lateral and dorsal cilia, which are all single, not compound (Fig. 3). The lateral cilia in a typical fila-

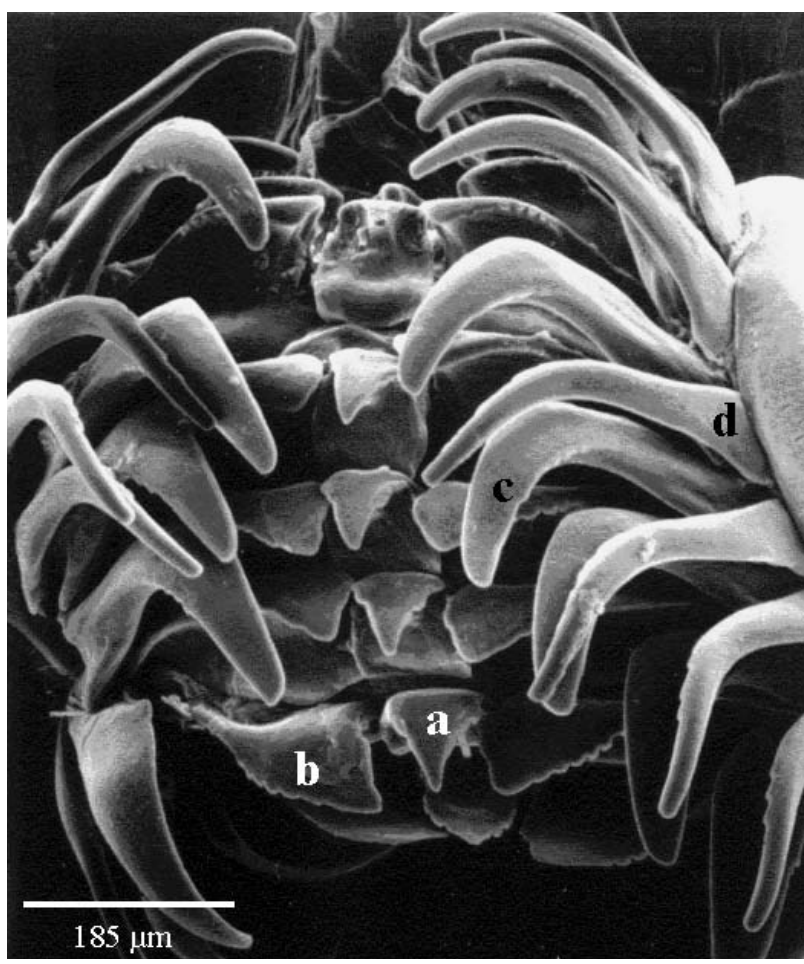

Fig. 1. Stereoscan micrograph of the taenioglossan radula of Crepidula fecunda. a: rachidian tooth; b: lateral teeth; c: internal marginal teeth; d: external marginal teeth 


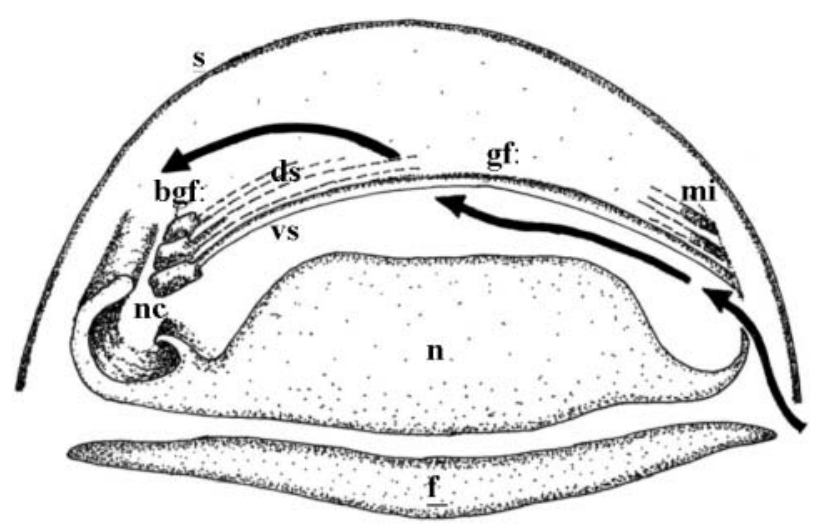

Fig. 2. Diagrammatic transverse section of Crepidula fecunda (anterior view). bgf: bulbar region on distal margin of gill filaments; ds: dorsal surface of lamella; f: foot; gf: gill filaments; mi: insertion of gill in mantle; n: neck; nc: neck canal; s: shell; vs: ventral surface of gill lamella. Arrow: direction of current within pallial cavity ment from the central part of the lamella of a limpet of shell length 3 to $5 \mathrm{~cm}$ have a mean $\pm \mathrm{SD}$ length of $20 \pm 3.5 \mu \mathrm{m}$, whereas the ventral cilia, which face the incoming water current and entirely cover the front of the filament, are much shorter (mean length $6.6 \pm$ $1.0 \mu \mathrm{m})$. In the distal region of the filament the ventral cilia cover a larger area, enveloping the entire bulb at the filament tip (Fig. 4). The dorsal cilia are also short (mean length $6.9 \pm 0.7 \mu \mathrm{m}$ ).

Particle entrainment occurs mostly on that face of the gill lamella that is oriented towards the inhalent water current, i.e. the ventral surface. The particles are retained in a mucous net which covers this surface (Fig. 5). This mucus-particle complex is then transferred to the distal region of the lamella by the ventral cilia at a mean velocity $1.32 \pm 0.93 \mathrm{~mm} \mathrm{~s}^{-1}$ (range 0.49 to $2.57 \mathrm{~mm} \mathrm{~s}^{-1}$, shell length 3 to $5 \mathrm{~cm}$ ). Here they accumulate on the filament bulbs to form a mucous string which extends along the length of the lamella (Fig. 6).
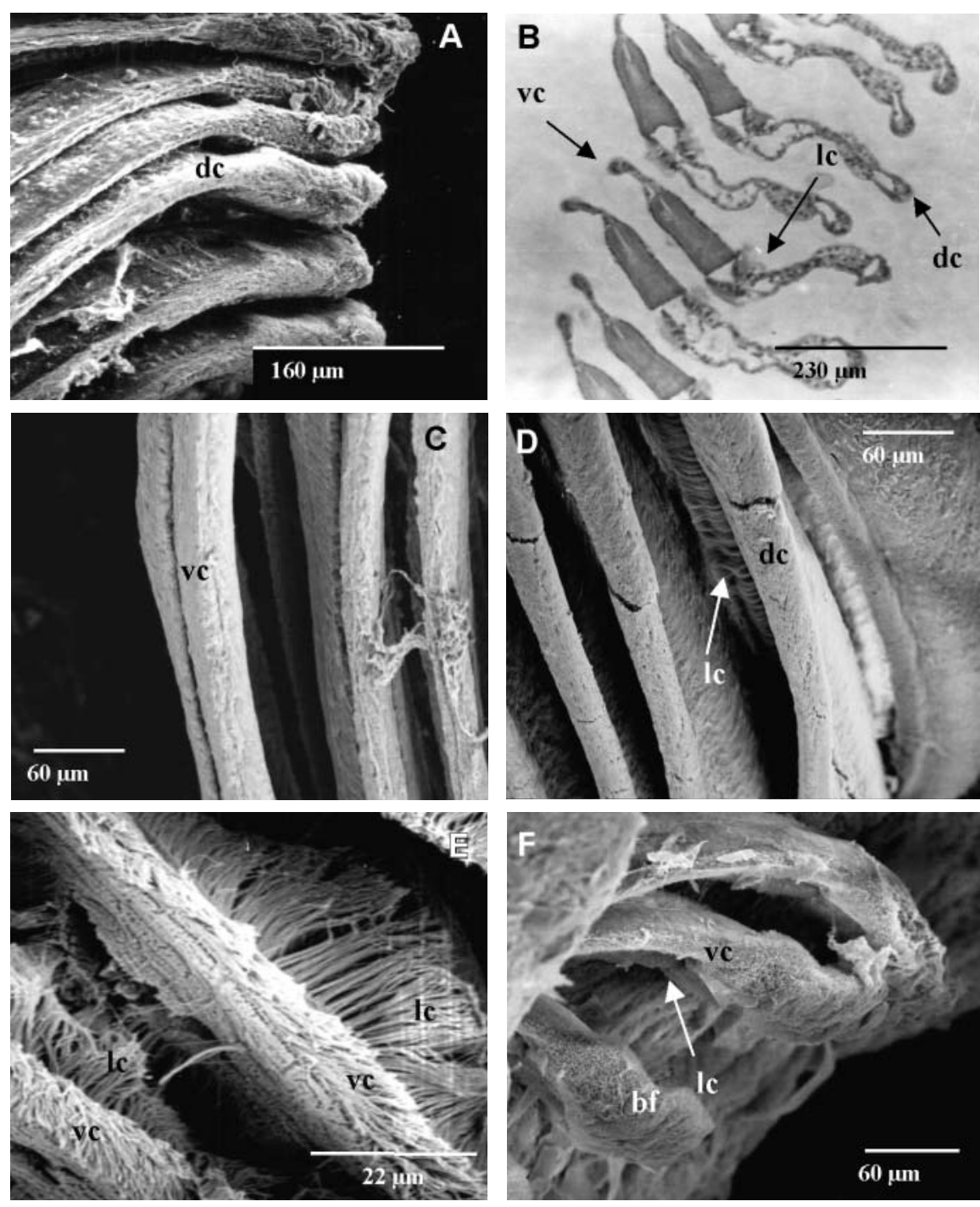

Fig. 3. Scanning electron micrographs (except B, histological section) of the gill of Crepidula fecunda. (A) Dorsal surface of lamella in distal region. (B) Transverse section of lamella showing a series of branchial filaments. (C) Ventral surface of lamella. (D) Dorsal surface of branchial filaments. (E) Ventral view of branchial filaments. (F) Distal region of branchial filaments on the right-hand side of the gill. bf: bulb of branchial filament; dc: dorsal cilia; lc: lateral cilia; vc: ventral cilia 

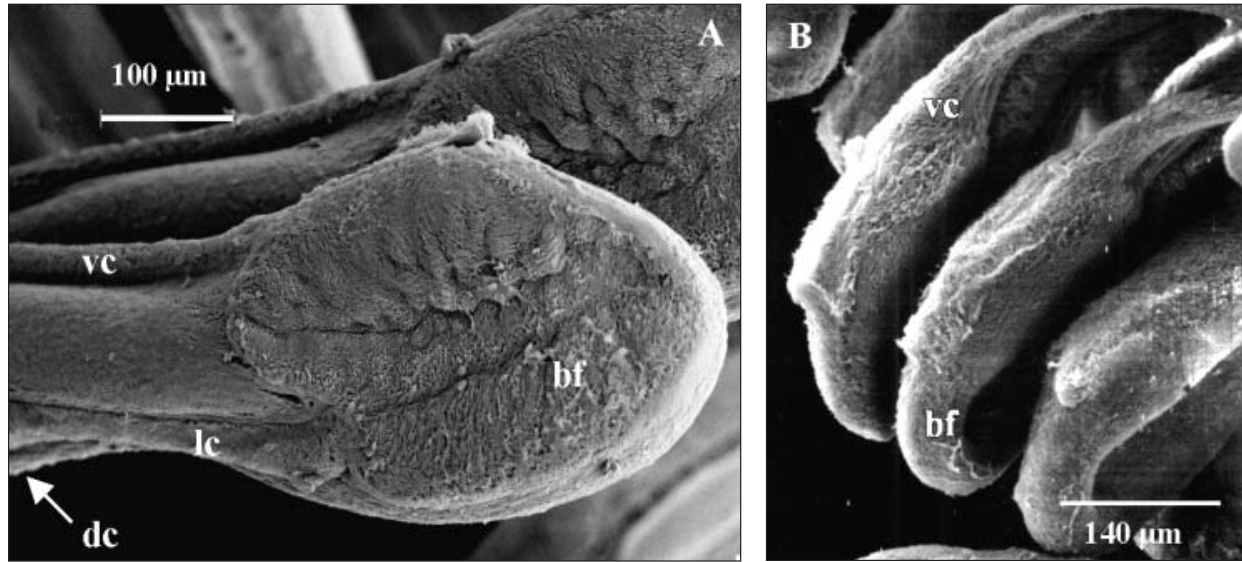

Fig. 4. Scanning electron micrographs of the distal margin of the lamella of Crepidula fecunda, showing the terminal bulbs on the branchial filaments. (A) Lateral view. (B) Ventral view. bf: bulb of branchial filament; dc: dorsal cilia; lc: lateral cilia; vc: ventral cilia

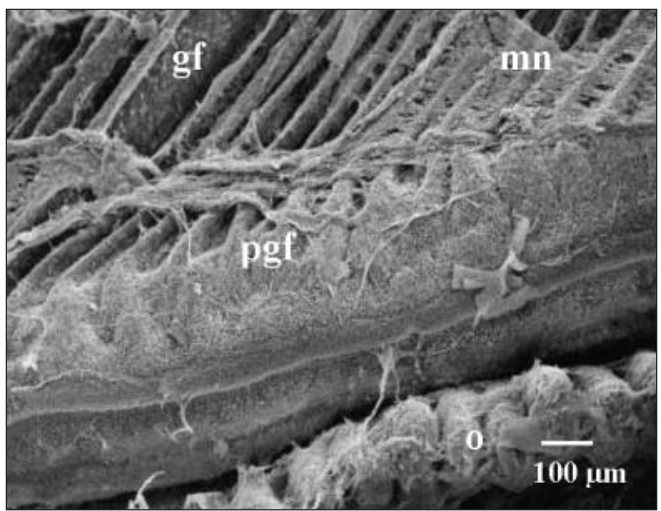

Fig. 5. Scanning electron micrograph of the basal region of the gill of Crepidula fecunda, showing the mucous net (mn) on the ventral surfaces of the filaments. gf: gill filaments;

o: osphradium; pgf: proximal region of gill filaments

This is one of 2 such strings to be formed. Some particles are not captured on the ventral surface of the lamella but pass between the filaments and are entrained on the dorsal surface, perhaps also by means of a mucous net. These particles on the dorsal face are also moved distally, but on arrival at the bulb they are transported by ciliary action across the tip and accumulate in a second mucous string on the ventral surface of the bulb parallel and distal to the first. As material continues to accumulate, the 2 mucous strings merge to form a single large string which covers the entire ventral surface of the bulb. However, there is no equivalent of the ciliated food tract found on the ventral margin of the demibranch in bivalve molluscs (Ward et al. 1991), and the Crepidula gill therefore lacks the means to move the mucous string anteriorly or posteriorly. Instead, the string is transferred to a muscular, spiral groove in the neck, the food canal.

The gill lamella itself is essentially flat, although the animal is able to adjust the positions of the filaments as if they were interconnected, especially in the distal region. Endoscopic observations revealed that towards the right-hand side of the gill there is a region in which several branchial filaments are thrown into folds, giving a pleated appearance (Fig. 7). This appears to be the point at which the neck comes into contact with the gill when removing the mucous string.

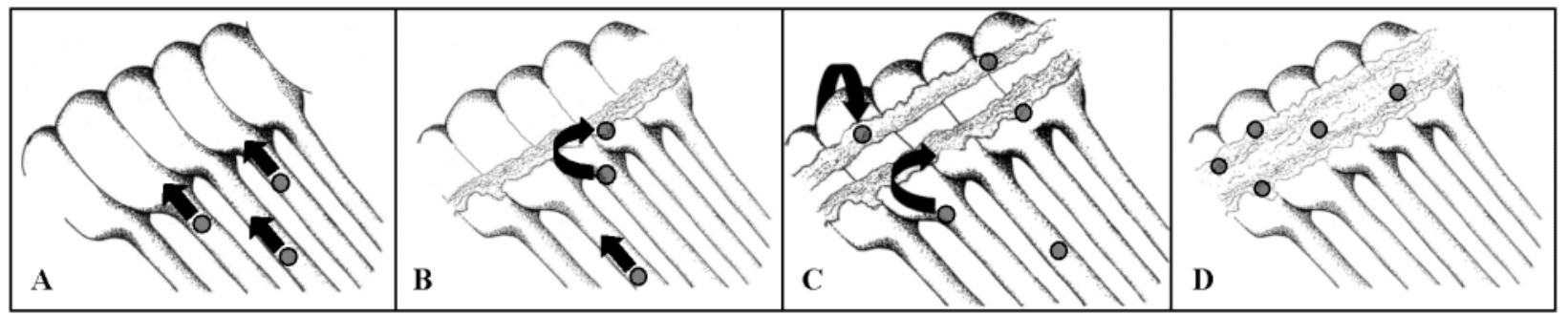

Fig. 6. Diagrammatic representation from endoscope observations of particle accumulation in mucous strings on the terminal bulbs of the branchial filaments of Crepidula fecunda (ventral view). Direction of particle transport is shown by arrows. (A) Entrained particles, loosely bound in mucus (not shown), move distally on the ventral surfaces of the filaments. (B) These particles from the ventral surface of the gill lamella are consolidated into a mucous string which extends across the ventral surfaces of the filament bulbs at right angles to the filaments. (C) Particles from the dorsal surface of the lamella traverse the margins of the bulbs and form a second mucous string parallel and distal to the first. (D) As particles continue to accumulate, the mucous strings thicken until they coalesce into a single string, which is then transferred to the food canal in the neck 


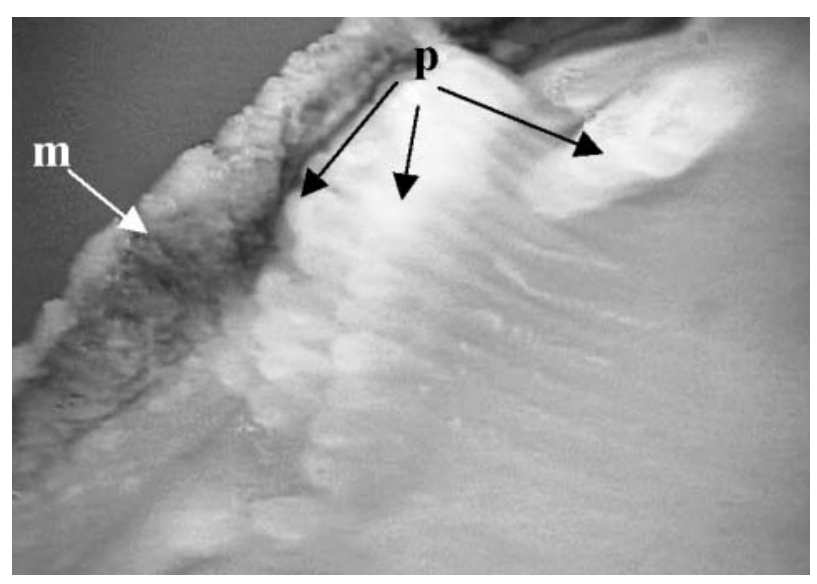

Fig. 7. Image from a dissecting microscope showing the folded or pleated region of the gill lamella of Crepidula fecunda. m: mantle; p: pleats or folds

\section{The food canal}

The neck of Crepidula fecunda is highly flexible and can extend through a considerable arc with respect to its angle of insertion into the body. The food canal is a deep groove which crosses the entire margin of the right side of the neck (Figs. $2 \& 8 \mathrm{~A}$ ). The animal can close the canal by opposing the margins or crests, and this appears to be the normal state when the mucous cord is being transported. The cord moves down the canal in a spiral action effected by muscles, which can be seen as ridges in the canal wall in SEM micrographs (Fig. 8B), not by ciliary action as suggested by Orton (1912). To remove the mucous string from the branchial filaments, the neck is brought into contact with the distal margin of the gill (Fig. 9). The string is secured and pulled into the food canal by muscular action, and the neck is then withdrawn slowly from the lamella. At the point of separation from the lamella, the anterior and posterior parts of the string are twisted together like a skein of 2-ply wool or a double braid, forming the compact mucous cord which passes down the spiral canal towards the mouth. This process occurs much more rapidly than the accumulation of the mucous string on the margin of the lamella, and the string is therefore completely removed by the neck canal. The neck then disengages completely from the gill lamella as the cord continues down the canal. When the proximal part of the cord reaches the buccal region, the radula emerges to grasp the cord and pull it into the

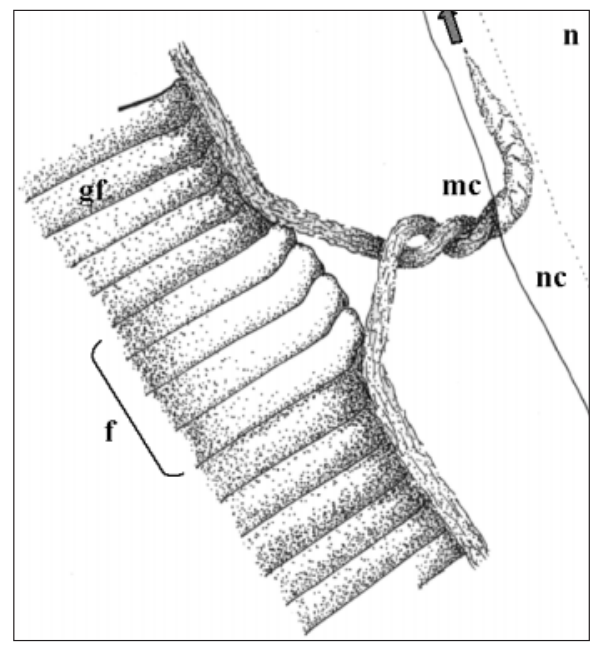

Fig. 9. Diagrammatic representation from endoscope observations of the transfer of the consolidated mucous string from the gill lamella of Crepidula fecunda to the food canal in the neck (ventral view). The arrow indicates the path taken by the mucous cord towards the mouth. f: filaments in pleated region of lamella (for clarity the pleat itself is not shown); gf: gill filaments; mc: mucous cord formed by twisting of the mucous thread; n: neck; nc: neck canal. Note that the number of filaments that are folded into the pleat is greater than that shown

\section{A}

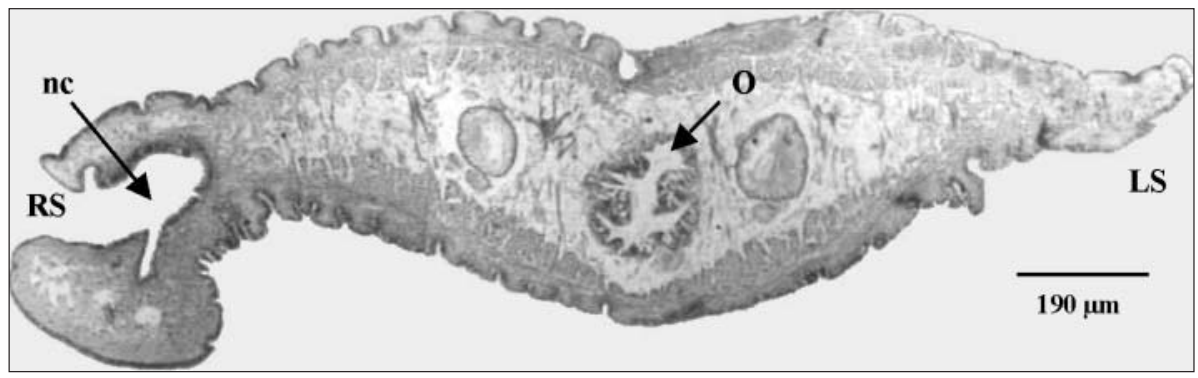

B

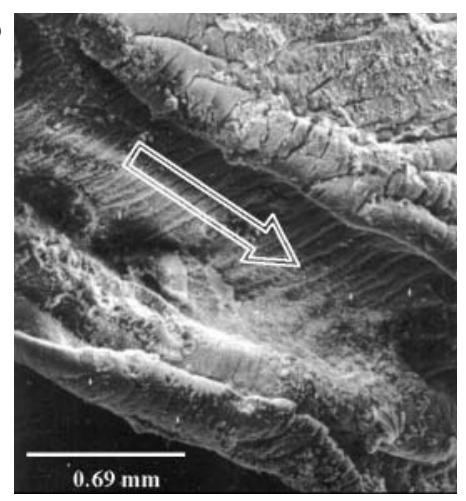

Fig. 8. (A) Transverse section through the neck of a female Crepidula fecunda. LS: left side; RS: right side; nc: neck canal; o: oesophagus. (B) Scanning electron micrograph of the central region of the neck canal of $C$. fecunda, showing muscular ridges in the canal wall. Arrow indicates direction of transport of mucous cord towards the mouth 

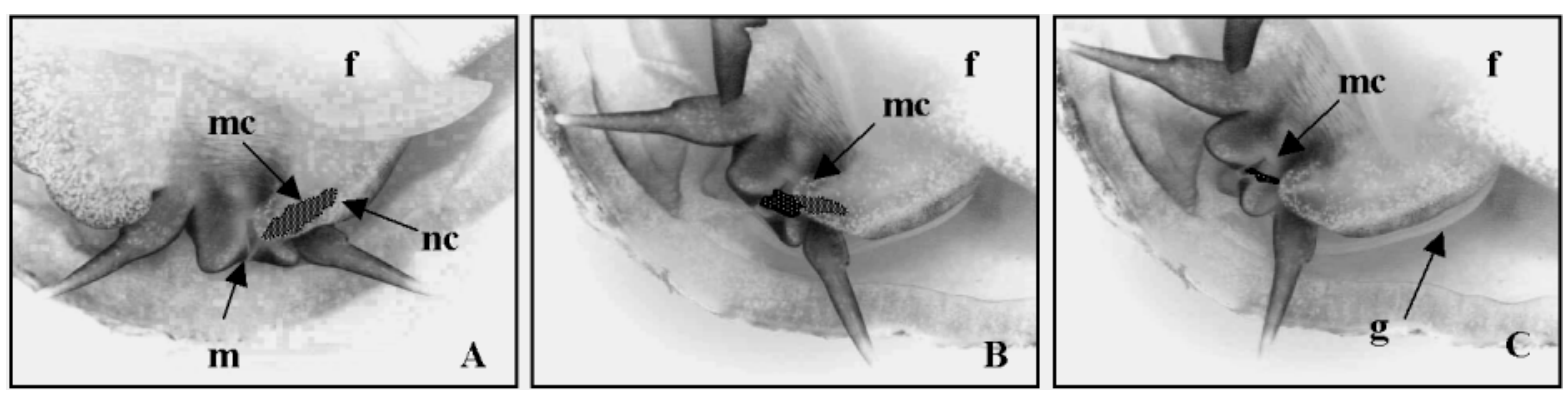

Fig. 10. Sequence of images from a dissecting microscope showing the transfer of the mucous cord from the neck canal to the mouth in Crepidula fecunda. The cord has been highlighted for clarity, the fine stippling indicating regions in which it lies within the canal, the coarse stippling regions in which it has emerged into the buccal region. (A) Cord still entirely within neck canal; (B) cord partially emerged from canal; $(\mathrm{C})$ cord completely outside canal and partially ingested. $\mathrm{f}_{\text {: foot; }} \mathrm{g}$ : gill; $\mathrm{m}$ : mouth mc: mucous cord; nc: neck canal

mouth by a series of rapid, ratchet-like movements (Fig. 10). The canal is now empty as material continues to accumulate in the mucous strings on the gill margin, and the neck remains disengaged from the gill until the lamellar margin is again loaded with food and the cycle is repeated. Thus, the handling of food material is continuous on the gill and discontinuous in the food canal, although the 2 components are well coordinated.

\section{The food pouch}

A small part of the mantle wall in the frontal region, close to the head, is modified by folding to form a cavity known as the food pouch (Fig. 11), described in Crepidula fornicata by Orton (1912). From the extreme right distal margin of the food pouch arises a projection of the mantle which is prehensile and can come into close contact with the last few branchial filaments, frequently covering them, although the degree of contact is variable. When the food concentration is high, this projection of the food pouch removes individual particles or small aggregates from that part of the mucous string on the filaments of the extreme distal region of the gill, i.e. the terminal region with which the projection makes contact. The projection was never observed to remove the mucous string per se. The relationship between the projection and the gill is dynamic, the former constantly adjusting its position with respect to the latter, but always remaining close to the filaments. The particles sequestered by the projection are transferred by temporary ciliary tracts to a cavity in the centre of the food pouch. A ciliated canal arising from the left side of the branchial insertion into the mantle also transports particles to the food pouch, which it enters on the left-hand side.

Within the cavity of the food pouch the particles and aggregates are concentrated and rotated continuously by ciliary action, resulting in the formation of a com- pact mucous ball as the material is bound up by mucus produced in this region (Fig. 12). In some specimens the radula was observed to seize the mucous ball, pull it into the mouth and ingest it. On other occasions, however, the ball was partially or completely taken into the mouth before being rejected and pushed by the radula and lips to the region outside the shell, forming pseudofaeces (Fig. 13). In some cases the mucous ball was expelled from the food pouch to the exterior without first being taken into the mouth. There
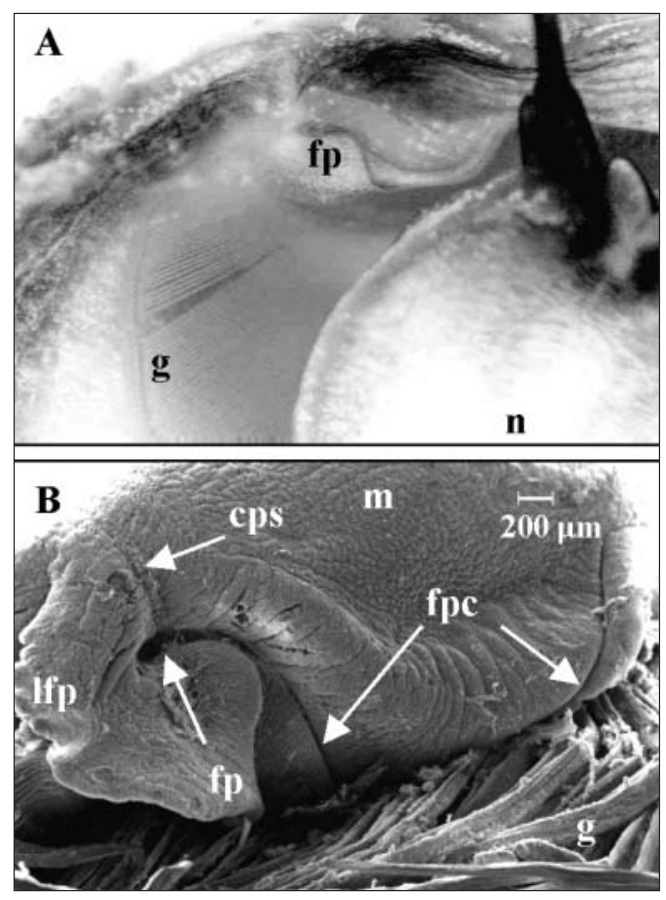

Fig. 11. Position of the food pouch in Crepidula fecunda (ventral aspect). (A) Image from dissecting microscope. (B) Scanning electron micrograph. cps: pseudofaeces channel; fp: food pouch; fpc: food pouch canal; g: gill; lfp: lip or projection of food pouch; m: mantle; n: neck 


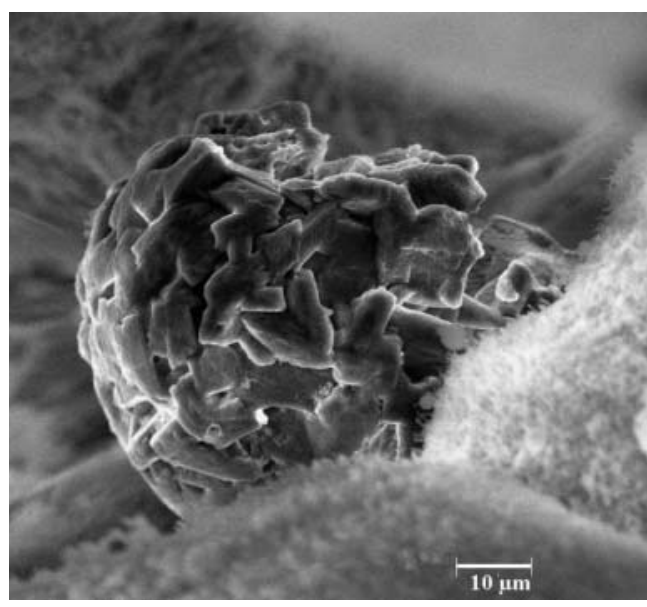

Fig. 12. Scanning electron micrograph of a mucous ball within the food pouch of Crepidula fecunda

is also a ciliated rejection tract which bypasses the food pouch, taking food material from the ciliated canal directly to the exterior. Preliminary observations suggest that these rejection mechanisms most commonly occur at high food concentrations.

\section{DISCUSSION}

The gastropod Crepidula fecunda is a protandric hermaphrodite living in chains or stacks of approximately 2 to 10 individuals, some of which are motile and others sessile. Many of these motile animals are adult males, which move around the chain impregnating the females, whereas others are juveniles. The sessile individuals are exclusively females, which deposit egg capsules on the substrate below the shell and then exhibit parental care of the capsule mass. In $C$. fecunda most females are sessile throughout their lives, but in other species of the genus the female is sessile during the incubation period but not necessarily for her entire life (Coe 1953, Gallardo 1977, Hoagland 1978, 1979).
The dual nature of the feeding system in Crepidula fecunda is adapted to the mode of reproduction. All motile individuals (juveniles and adult males) should be able to graze the substrate with the taenioglossan radula as they move, as suggested by Chaparro et al. (1998) for C. dilatata and shown in newly settled juveniles of C. convexa and C. adunca by Hoagland (1979) and Putnam (1964), respectively, but the non-incubating sessile females are limited to grazing the substrate below the head, which may account in part for the lower frequency of grazing in the females. Although Orton (1913-1915) made no reference to rasping of the substrate by the radula in C. fornicata, he did mention the role played by the radula in the ingestion of food obtained by suspension feeding. The emphasis on suspension feeding in C. fornicata by Orton (1913-1915) and subsequent authors (e.g. Newell \& Kofoed 1977, Eyster \& Pechenik 1988) may reflect this reduced substrate grazing by females. The radula is also used in suspension feeding by gastropods that use an external mucous food net, the food-laden net being seized by the radula and ingested (Declerck 1995).

The gill is poorly developed in early juveniles of Crepidula convexa, and there are few branchial filaments, those which are present being flat (Hoagland 1979), suggesting that during this developmental stage grazing the surface with the radula is the principal means of feeding. On the other hand, Eyster \& Pechenik (1988) showed that very early juveniles of $C$. fornicata are able to remove particles from the water column. In late juveniles of $C$. fecunda, at which stage the gill has fully developed, mucous strings originating from suspension feeding by the gill are ingested (this study), and even in individuals as small as $4 \mathrm{~mm}$ shell length the neck canal, which transports food material from the gill to the mouth, is clearly functional. From this stage onwards both the gill and the radula play a direct role in the acquisition of food. Phylogenetic aspects of suspension feeding in gastropods have been reviewed by Declerck (1995).

The effectiveness of the taenioglossan radula in grazing hard substrates is less than that of radulas with
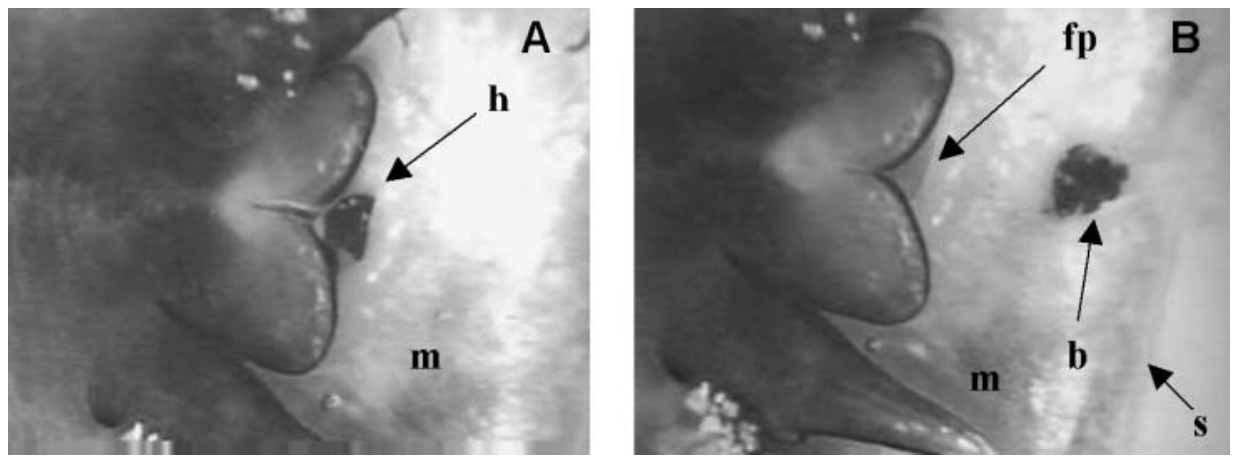

Fig. 13. Images from a dissecting microscope showing rejection of material from the food pouch by the lips and radula of Crepidula fecunda. (A) $\mathrm{Mu}-$ cous ball in the food pouch. (B) Mucous ball eliminated from the food pouch. b: mucous ball; fp: food pouch (empty); $\mathrm{m}$ : mantle; s: shell margin 
larger cusps on the teeth (Black et al. 1988). Furthermore, the teeth of the taenioglossan radula are chitinous and therefore erode faster than other types (Steneck \& Watling 1982), being most suitable for grazing soft substrates (Hawkins et al. 1989). Nevertheless, a gastropod with a taenioglossan radula may graze successfully if the species is highly motile (Underwood 1978). The present study shows that in adult males and in juveniles of Crepidula fecunda such a radula, combined with motility of the animal, complements the gill to provide 2 independent mechanisms for acquiring food from diverse sources.

The use of the radula by female Crepidula fecunda is also associated with the mode of reproduction. The sessile females rasp the substrate intensively before oviposition, possibly cleaning and preparing the substrate for the capsule mass, as well as providing a source of nutrition. During this process the radula erodes and loses most of the denticles.

The gill of Crepidula fecunda possesses a single lamella composed of filaments identical in all but length. The filaments are not permanently attached to their neighbours, and frequently separate from them. According to Werner (1953) C. fornicata also possesses a single gill lamella, and both faces participate in particle capture. We also observed cilia on both the dorsal and the ventral sides of the filaments of $C$. fecunda, as well as on both lateral surfaces. The ventral cilia face the inhalent water current, and the flow of water from the ventral to the dorsal surface of the lamella is maintained by the lateral cilia. Orton (1912, 1913-1915) observed the same pattern of ciliation in C. fornicata. Observations of particle movements on the gill of $C$. fecunda revealed that the dorsal as well as the ventral cilia are responsible for transfer of particles on the lamellar surface to the tips of the filaments. Similar observations have been made on $C$. fornicata by Werner (1953).

The role of mucus in particle filtration by Crepidula fornicata has been noted by Werner (1953). According to his account, mucus is concentrated in 2 places. The first is the point at which the inhalent current enters the mantle cavity, where a coarse mucous net is produced which traps most of the larger particles and some smaller particles. Particles captured here are transferred to a canal leading to a food pouch, where they are stored to await ingestion or rejection. In $C$. fecunda we did not observe this coarse mucous net, possibly because we did not focus on this region and were introducing only small particles to the ambient seawater. Nevertheless, the food pouch and its canal were clearly visible in $C$. fecunda. The second place in which Werner (1953) observed particle retention by mucus in C. fornicata was the gill lamella, where he described a fine mucous net on both the dorsal and the ventral surfaces which intercepts smaller particles that have passed through the coarse filter in the inhalent region. Most of the suspended particles are entrained by the mucous sheet on the ventral surface of the lamella, but those that pass through the lamella can be trapped by the mucous sheet on the dorsal surface. The mucous sheets containing particles are moved distally to the tips of the filaments. Our endoscopic observations of C. fecunda and our SEM micrographs revealed a mucous net on the ventral side of the lamella. We also observed the active role played by cilia in transporting it to the distal margin, but we were unable to observe the dorsal surface clearly, although it is probable that it too is covered by mucus, as described by Werner (1953) for C. fornicata. Thus the laterofrontal cirri typically found in bivalves are absent in Crepidula, in which mucus plays a greater role in the entrainment of particles on the lamella surface. The rate at which trapped particles move along the filament to the distal margin (mean $1.32 \mathrm{~mm} \mathrm{~s}^{-1}$ ) is about 4 times that at which they are moved along the filaments of the mussel Mytilus edulis (mean $0.32 \mathrm{~mm} \mathrm{~s}^{-1}$, Ward et al. 1991).

The loose connection between branchial filaments in Crepidula fecunda, also observed in C. fornicata by Orton (1913-1915), allows the lamella to fold in such a way that it forms a pleated area on the right side of the gill, in the region where the neck comes into contact with the filaments to remove the mucous string. This pleat is quite distinct from the rest of the gill, which is flat, and is not always present. Its function may be to orient the neck to the correct position on the gill and to facilitate the initial introduction of the mucous string into the neck canal, a difficult task were the gill completely flat and featureless.

The distal margin of the lamella, composed of the bulbous tips of the filaments, cannot move laterally, nor are there any ciliary tracts equivalent to those on the ventral margin of the typical bivalve demibranch, which continuously transfer the material anteriorly to the palps, thereby clearing the gill. Thus there is no mechanism in Crepidula fecunda whereby particles entrained in the mucous string(s) can leave the gill by lateral transport. The margin of the lamella serves only as a storage area for such mucous-bound particles. When sufficient material has accumulated and the 2 mucous strings have merged, the neck is brought into contact with the pleated area on the gill and the single, thick string is removed from the filaments. Unlike the ventral food tracts of the typical bivalve gill, which remove mucus-bound particulate material from the gill continuously, regardless of the amount present, the filament margins in $C$. fecunda transfer the mucous string to the next stage (the neck canal) intermittently, a mechanism that may be a means of conserving energy. We are examining the frequency at which the 
string is removed in relation to the concentration of seston in the water.

The means by which the mucous strings form on the distal margin of the lamella in Crepidula fecunda is a consequence of the sites of entrainment of particles and the distribution of the ciliary tracts on the filaments. Particles captured on the ventral surfaces of the filaments are transported distally to the ventral surfaces of the bulbs at the tip of the filaments. This material forms the more basal of the 2 mucous strings, which lie parallel to the margin of the lamella on the ventral surface of the bulbs. Particles intercepted on the dorsal surface of the lamella are also transported distally, but these traverse the tips of the filaments to arrive on the ventral surface of the bulb, where they form the second, more distal of the 2 strings that initially form. Thus the terminal bulb is heavily ciliated. Orton (1912) and Werner (1953) also recorded the transfer of particles from the dorsal surface of the lamella to the ventral region of the bulb of the branchial filament in C. fornicata. In $C$. fecunda we observed that before the 2 mucous strings merge, the distal string contains less material than the proximal string because more particles are trapped on the ventral surface of the lamella, which faces the inhalent current, than on the dorsal surface. Werner (1953) suggested a similar inequality in the sizes of the 2 mucous strings in C. fornicata.

Material removed from the lamella by the ciliated projection on the food pouch is transferred to the food pouch by ciliary currents on the mantle and retained there. Within the cavity of the food pouch, loosely compacted particles begin to rotate, apparently in the presence of copious amounts of mucus, to form a mucous ball. Orton (1912) described the formation of a pellet in the food pouch of Crepidula fornicata associated with the presence of glandular cells and cilia, observations that Werner (1953) later used to explain the rotation and compaction of particles in the food pouch. According to Werner (1953), the purpose of the food pouch in C. fornicata is to store particles, not only for subsequent ingestion but also for rejection as pseudofaeces. Our observations on C. fecunda are consistent with this interpretation. For example, although in many cases the mucous ball is removed from the food pouch by the radula for ingestion, on other occasions the radula and lips are used to expel the ball from the mantle region, producing pseudofaeces. The rejected ball may be pushed the entire distance to the shell margin, or it may be deposited on the mantle wall for ciliary rejection tracts to complete the task. The precise mechanism of psedofaeces production is not clear.

The fate of the particles in the food pouch may depend on factors such as food availability, and it has been suggested that particle selection may take place in the food pouch of Crepidula fornicata according to particle size or quality (Orton 1913-1915) and quantity (Werner 1953), although there is no empirical evidence. Such a selection mechanism would be advantageous in the estuarine, intertidal or nearshore environments in which Crepidula species generally live. For example, many populations of $C$. fecunda are intertidal and are exposed to considerable qualitative and quantitative variations in seston during the tidal cycle, so that a means of rejecting excess material is essential and the capability of sorting particles according to size and quality is desirable. The ability to store particles, whether on the gill lamella or in the food pouch, is also adaptive in this context and may conserve energy, since it does not require continuous transport and ingestion of particles. More importantly, particle storage decreases the time the radula must spend handling the mucous cord in the food canal and the material in the food pouch, allowing the radula to rasp the substrate and thereby enhance and diversify the food. The ability to exploit the organic material on the substrate as well as particles in suspension is also advantageous in intertidal and shallow subtidal environments in which the particle load may vary considerably.

In this paper we have established the mechanisms by which Crepidula fecunda acquires, retains and processes food both by suspension feeding and by rasping the substrate. Future investigations will be required to determine the feeding response to variations in the quality and quantity of the suspended particles and of the biofilm on the substrate, especially the role of the food pouch and the time spent by the radula on different activities. The transition from rasping in early juveniles to a combination of rasping and suspension feeding in adults should also be examined, and there is a need for more information on the feeding mechanism, particularly the use of the radula, in females incubating capsule masses.

Acknowledgements. We thank the staff of the Estación Experimental of the Universidad Austral de Chile at Quempillén, Chiloé, where the research was carried out. Ms. Lisa Lee and Mr. Ricardo Silva assisted with SEM work, and Ms. Marcela Oróstegui with the preparation of figures and video sequences. The research was supported by grants to O.R.C from FONDECYT 1980984 (Chile) and the Dirección de Investigación of the Universidad Austral de Chile, and by a Canadian International Development Agency (CIDA) award to Memorial University of Newfoundland and the Universidad Austral de Chile.

\section{LITERATURE CITED}

Black R, Lymbery A, Hill A (1988) Form and function: size of radular teeth and inorganic content of faeces in a guild of grazing molluscs at Rottnest Island, Western Australia. J Exp Mar Biol Ecol 121:23-35 
Cañete JI, Ambler RP (1992) Desarrollo intracapsular del gastrópodo comestible Calyptraea (Trochita) trochiformis (Born, 1778), en Chile. Rev Chil Hist Nat 65:255-266

Chaparro OR, Bahamondes-Rojas I, Vergara AM, Rivera AA (1998) Histological characteristics of the foot and locomotory activity of Crepidula dilatata Lamarck (Gastropoda: Calyptraeidae) in relation to sex changes. J Exp Mar Biol Ecol 223:77-91

Coe WR (1953) Influences of association, isolation and nutrition on the sexuality of snails of the genus Crepidula. J Exp Zool 122:5-19

Declerck CH (1995) The evolution of suspension feeding in gastropods. Biol Rev 70:549-569

Eyster LS, Pechenik JA (1988) Comparison of growth, respiration, and feeding of juvenile Crepidula fornicata (L.) following natural or KCl-triggered metamorphosis. J Exp Mar Biol Ecol 118:269-279

Fretter V (1984) Prosobranchs. In: Tompa AS, Verdonk NH, van der Biggelaar JAM (eds) The Mollusca, Vol 7. Reproduction. Academic Press, New York, p 1-45

Gallardo CS (1977) Two modes of development in the morphospecies Crepidula dilatata (Gastropoda: Calyptraeidae) from southern Chile. Mar Biol 39:241-251

Hawkins SJ, Watson DC, Hill AS, Harding SP, Kyriakides MA, Hutchinson S, Norton TA (1989) A comparison of feeding mechanisms in microphagous, herbivorous intertidal prosobranchs in relation to resource partitioning. J Molluscan Stud 55:151-165

Hendler G, Franz DR (1971) Population dynamics and life history of Crepidula convexa Say (Gastropoda: Prosobrancha) in Delaware Bay. Biol Bull 141:514-526

Hoagland KE (1978) Protandry and evolution of environmentally-mediated sex change: a study of the Mollusca. Malacologia 17:365-391

Hoagland KE (1979) The behavior of three sympatric species of Crepidula (Gastropoda: Prosobranchia) from the Atlantic, with implications for evolutionary ecology. Nautilus 94:143-149

Editorial responsibility: Roger Hughes (Contributing Editor), Bangor, Wales, UK
Hughes RN (1986) A functional biology of marine gastropods. Croom Helm, London

Kohn AJ (1983) Feeding biology of gastropods. In: Saleuddin ASM, Wilbur KM (eds) The Mollusca, Vol 3. Physiology, Part 2. Academic Press, New York, p 1-63

Newell RC, Kofoed LH (1977) Adjustment of the components of energy balance in the gastropod Crepidula fornicata in response to thermal acclimation. Mar Biol 44:275-286

Orton JH (1912) The mode of feeding of Crepidula, with an account of the current-producing mechanism in the mantle cavity, and some remarks on the mode of feeding in gastropods and lamellibranchs. J Mar Biol Assoc UK 9: $444-478$

Orton JH (1913-1915) On ciliary mechanism in Brachiopods and some Polychaetes, with a comparison of the ciliary mechanisms on the gills of Molluscs, Protochordata, Brachiopods, and Cryptocephalous polychaetes, and an account of the endostyle of Crepidula and its allies. J Mar Biol Assoc UK 10:283-311

Purchon RD (1977) The biology of Mollusca. Pergamon Press, New York

Putnam DA (1964) The dispersal of young of the commensal gastropod Crepidula adunca from its host Tegula funebralis. Veliger 6:63-66

Steneck RS, Watling L (1982) Feeding capabilities and limitation of herbivorous molluscs: a functional group approach. Mar Biol 68:299-319

Underwood AJ (1978) An experimental evaluation of competition between three species of intertidal prosobranch molluscs. Oecologia 33:185-202

Ward JE, Beninger PG, MacDonald BA, Thompson RJ (1991) Direct observations of feeding structures and mechanisms in bivalve molluscs using endoscopic examination and video image analysis. Mar Biol 111:287-291

Werner B (1953) Über den Nahrungserwerb der Calyptraeidae (Gastropoda Prosobranchia). Morphologie, Histologie und Funktion der am Nahrungserwerb beteiligten Organe. Helgol Wiss Meeresunters 4:260-315

Submitted: February 1, 2001; Accepted: August 23, 2001 Proofs received from author(s): April 26, 2002 